\title{
Avaliação sensitiva, motora e cistométrica de cães com lesão medular crônica, submetidos ao transplante de células-tronco mesenquimais derivadas de tecido adiposo ${ }^{1}$
}

Thais Gabrielle F.S.L. Silva ${ }^{2 *}$, Fagner M. Oliveira ${ }^{3}$, Letícia Fracaro ${ }^{4}$, Carlos E. Silva ${ }^{5}$, Carmen L.K. Rebelatto ${ }^{4}$, Claudia T. Pimpão ${ }^{6}$, Paulo R.S. Brofman ${ }^{4}$ e José A.V. Junior ${ }^{6}$

\begin{abstract}
Silva T.G.F.S.L., Oliveira F.M., Fracaro L., Silva C.E., Rebelatto C.L.K., Pimpão C.T., Brofman P.R.S. \& Vill Junior J.A. 2018. [Sensory, motor and cystometric evaluation of dogs with chronic spinal cord injury submitted to mesenchymal stem cell transplantation.] Avaliação sensitiva, motora e cistométrica de cães com lesão medular crônica, submetidos ao transplante de células-tronco mesenquimais derivadas de tecido adiposo. Pesquisa Veterinária Brasileira 38(10):1955-1965. Departamento de Medicina Veterinária, Pontifícia Universidade Católica do Paraná, Rua Imaculada Conceição 1155, Prado Velho, Curitiba, PR 80215-901, Brazil. E-mail: thais.gabi.ferreira@gmail.com

The use of stem cells in injury repair has been extensively investigated. In this study, we examined the therapeutic effects of two transplants $\left(12 \times 10^{6}\right.$ cells/transplantation) of allogenic adipose-derived stem cells (ASCs) in 11 dogs with chronic spinal cord injury. ASC were cultured in vitro, proliferation and cell viability were evaluated. Cell suspensions were prepared and administered in the intradural space, with a one-week interval between transplants. The animals were submitted to clinical, laboratory, radiographic, tomographic, sensory, motor and cystometric evaluations. Most of the animals were not a breed defined $(63.63 \%)$, the same proportion for females affected, predominance of vertebral subluxation fracture was observed (81.81\%). Before and after the transplants no hematological changes were observed, three animals (27.27\%) presented bacterial cystitis, and in relation to motor, cystometry and sensitivity, no improvement was observed; the rates were maintained before and after transplants, predominance of nociceptive absence in most animals (72.73\%), and paraplegia and urinary incontinence in the same proportion. In this study it was concluded that the use of ADSCs for the treatment of dogs with chronic spinal cord injury is safe, with a slight improvement in bladder function, but without significantly clinical improvement.
\end{abstract}

INDEX TERMS: Canine, spinal cord compression, cell transplation, motor activity, urodynamics, cell terapy, dogs, surgery.

\footnotetext{
${ }^{1}$ Recebido em 5 de dezembro de 2017.

Aceito para publicação em 13 de dezembro de 2017.

Parte da dissertação de Mestrado do primeiro autor.

${ }^{2}$ Departamento de Medicina Veterinária, Pontifícia Universidade Católica do Paraná (PUCPR), Rua Imaculada Conceição 1155, Prado Velho, Curitiba, PR 80215-901, Brasil.*Autor para correspondência: thais.gabi.ferreira@gmail.com

${ }^{3}$ Mestrando do Programa de Pós-Graduação em Ciência Animal (PPGCA), Pontifícia Universidade Católica do Paraná (PUCPR), Rua Imaculada Conceição 1155, Prado Velho, Curitiba, PR 80215-901, Brasil.

${ }^{4}$ Núcleo de Tecnologia Celular da Pontifícia Universidade Católica do Paraná (PUCPR), Rua Imaculada Conceição 1155, Prado Velho, Curitiba, PR 80215-901.

${ }^{5}$ Policlínica São Vicente de Paula, Rua Vereador Romeu Lauro Werlang 1343, Centro, Francisco Beltrão, PR 85601-020.

${ }^{6}$ Docente, Programa de Pós-Graduação em Ciência Animal (PPGCA), Pontifícia Universidade Católica do Paraná (PUCPR), Rua Imaculada Conceição 1155, Prado Velho, Curitiba, PR 80215-901.
}

RESUMO.- A utilização de células-tronco na reparação de lesões tem sido extensivamente investigada. Neste estudo, examinamos os efeitos terapêuticos de dois transplantes $\left(12 \times 10^{6}\right.$ céls/transplante) de células-tronco mesenquimais alogênicas derivadas do tecido adiposo (CTDAs) em 11 cães com lesões crônicas traumáticas toracolombares da medula espinhal. As CTDAs foram foram cultivadas in vitro, a proliferação e a viabilidade foram avaliadas. As suspensões foram expandidas e administradas no espaço intradural com intervalo de uma semana entre transplantes. Os cães foram submetidos à avaliações clínicas, laboratoriais, radiográficas, tomográficas, sensitivas, motoras e cistométricas. A maioria dos animais não tinha raça definida $(63,63 \%)$, mesma proporção para o acometimento de fêmeas e foi observada predominância de 
fratura com subluxação vertebral (81,81\%). Na comparação dos cães pré e pós-transplante não foram observadas alterações hematológicas e três animais $(27,27 \%)$ apresentaram cistite bacteriana. Em relação a sensibilidade, motricidade e cistometria, também não houve alterações significativas dos índices antes e pós transplantes, sendo observado a ausência nociceptiva na maioria dos animais $(72,73 \%)$, paraplegia e incontinência urinária na mesma proporção. Neste estudo concluiu-se que o protocolo utilizado de transplante de CTDAs, demonstrou ser um tratamento seguro para cães com lesão medular crônica, com melhora discreta da funcionalidade vesical, porém sem melhora clínica significativa.

TERMOS DE INDEXAÇÃO: Caninos, compressão da medula espinhal, transplante de células, atividade motora, urodinâmica, terapia celular, cirurgia.

\section{INTRODUÇÃO}

A principal causa de atendimento neurológico em animais de companhia é o traumatismo medular, e a gravidade depende da velocidade, do grau e da duração da lesão compressiva (Green et al. 2008, Fletcher et al. 2016). Os déficits neurológicos em consequência da lesão aguda da medula espinhal podem resultar de secção mecânica (lesão primária) das vias neuronais imediatamente após o trauma, assim como de lesão tecidual tardia (secundária) que ocorre em um período de minutos a dias após a primária. Essas lesões tardias relacionam-se ao desencadeamento de uma cascata de eventos destrutivos celulares, locais, sistêmicos, que promovem isquemia, hipóxia, edema e diversos eventos bioquímicos prejudiciais à medula espinhal (Osako et al. 2008, Lorenz \& Kornegay 2011, Dewey \& Fossum 2013).

0 traumatismo na medula espinhal causa perdas motoras e sensitivas, alterações no funcionamento do sistema urinário, além de comprometimento intestinal, respiratório, circulatório, sexual e reprodutivo (Park et al. 2012). As lesões medulares em nível torácico e lombar resultam em disfunções do trato urinário, como a hiperatividade da bexiga urinária, dissinergia vesico-esfincteriana e retenção urinária (Forner 2011, Dewey \& Fossum 2013, Fletcher et al. 2016).

Apesar de diversas terapias medicamentosas ou celulares bem-sucedidas, ainda não foi observado a recuperação das lesões do parênquima medular lesionado (Fitzmaurice 2011, Granger et al. 2014).

Recentemente, o transplante de células-tronco tem sido considerado uma opção promissora para o tratamento de distúrbios neurológicos (Pluchino et al. 2005), incluindo lesões medulares agudas (Lee et al. 2011, Penha et al. 2014) e crônicas (Sarmento et al. 2014, Lee et al. 2015). Estudos pioneiros usaram células-tronco neurais como fonte celular para a regeneração do sistema nervoso (Fine 1994). No entanto, devido à sua disponibilidade limitada, fontes alternativas para o transplante de células-tronco, tais como embrionárias e células-tronco adultas também têm sido investigadas (Kadiyala et al. 1997, McKay 1997, Kopen et al. 1999, Pluchino et al. 2005, Kang et al. 2006, Lim et al. 2007). As células-tronco mesenquimais derivadas do tecido adiposo (CTDAs) podem ser facilmente obtidas, expandidas in vitro e diferenciadas em fenótipos neuronais no cérebro danificado e medula espinhal (Zuk et al. 2002, Blecker et al. 2017), e desta forma, podem ser uma boa opção terapêutica para animais com lesão medular.

As CTDAs apresentam características importantes para a pesquisa clínica devido a liberação de fatores bioativos que tem ação parácrina, são pouco imunogênicas e têm potencial imunomodulador (Doorn et al. 2012). Apesar dos resultados positivos obtidos em modelos experimentais usando uma variedade de espécies animais e recentes avanços significativos no transplante celular, o desenvolvimento de estratégias eficazes para tratar lesões medulares crônicas continua sendo um grande desafio clínico (Lim et al. 2007, Wright et al. 2011, Donnelly et al. 2012, McMahill et al. 2015, Penha et al. 2014, Hoffman \& Dow 2016).

A utilização da terapia celular no trauma medular pode ser uma importante alternativa terapêutica por ser ainda uma doença intratável e incurável (Webb et al. 2010, Mothe \& Tator 2012, Antonic et al. 2013). Desta forma, o objetivo deste estudo foi avaliar a segurança e eficácia da utilização das CTDAs alogênicas em cães com lesão medular toracolombar crônica.

\section{MATERIAL E MÉTODOS}

Animais. Onze cães adultos, com idade entre dois e sete anos e histórico de lesão medular toracolombar crônica (entre 6 meses e 2 anos), sem doença concomitante, foram submetidos a avaliações clínicas para determinar a gravidade da lesão, conforme escala de Penning et al. (2006) e avaliações laboratoriais, radiográficas, tomográficas, sensitivas e cistométricas.

Avaliação do grau de lesão. A gravidade dos sinais neurológicos foi classificada da seguinte forma: grau I = apenas hiperestesia espinhal, grau II = paraparesia ambulatorial, ataxia, déficits proprioceptivos, grau III = paraparesia não ambulatorial, grau IV = paraplegia com nocicepção e grau $\mathrm{V}=$ paraplegia com perda de nocicepção (Penning et al. 2006).

Avaliações laboratoriais, radiográficas, tomográficas, sensitivas e cistométricas. Foram realizados exames urinários por meio da coleta por cistocentese, guiados por ultrassonografia e hematológicos (hemograma e provas bioquímicas de ureia, creatinina, albumina, ALT - alanina aminotransferase e FA - fosfatase alcalina) por meio de coleta de sangue da veia jugular externa. Esses exames foram realizados para avaliação pré-anestésica, para avaliar se os animais estariam aptos para a realização dos transplantes de CTDAs.

As avaliações de imagem, radiografia digital (em dupla projeção, laterolateral e dorsoventral) e tomografia computadorizada, visaram o diagnóstico exclusivo de duas condições, a primeira de fratura vertebral com subluxação secundária, em região toracolombar (Fig.1), enquanto que a segunda, a presença de hérnia discal do tipo I de Hansen, ou seja, quando há extrusão discal com a presença de material compressor (Dewey \& Costa 2016), também em região toracolombar (Fig.2).

Não fizeram parte do estudo condições diferentes destas, como discoespondilite, neoplasia, doença vertebral congênita ou degenerativa.

As avaliações sensitivas pré e pós-transplantes foram baseadas nas sensibilidades cutânea: dor superficial (também denominada de dor rápida, é uma dor aguda e bem localizada, testada por compressão da pele interdigital com pinça hemostática) e dor profunda (também denominada de dor lenta, é sentida como uma dor tipo queimação, contínua e mal localizada que tem origem na pele ou em estruturas mais profundas, testada com a compressão das falanges proximais do segundo e quarto dedos), a flexão simples do membro sem uma 
resposta consciente significa que o reflexo está presente, mas a nocicepção está ausente, conforme preceitos de Sharp \& Wheeler (2005) e Dewey et al. (2016).

Desta forma estabeleceu-se a seguinte classificação quanto à sensibilidade: 1 = presença de dores superficial e profunda, 2 = presença de dor superficial e ausência de dor profunda e 3 = ausência de dor superficial e profunda.

A avaliação cistométrica, que é em última análise o exame neurológico da bexiga, pode ser útil para o diagnóstico de afecções sediadas em todo o neuroeixo, desde o córtex cerebral até as raízes da cauda equina, sendo complementar ao exame neurológico (Fernández \& Bernardini 2010, Lorenz \& Kornegay 2011). Neste estudo a cistometria foi realizada utilizando o aparelho da marca Dynamed $^{\circledR}$, modelo Dynapack MPX816 equipado com um sensor para volume infundido e obedeceu à padronização da ICS (International

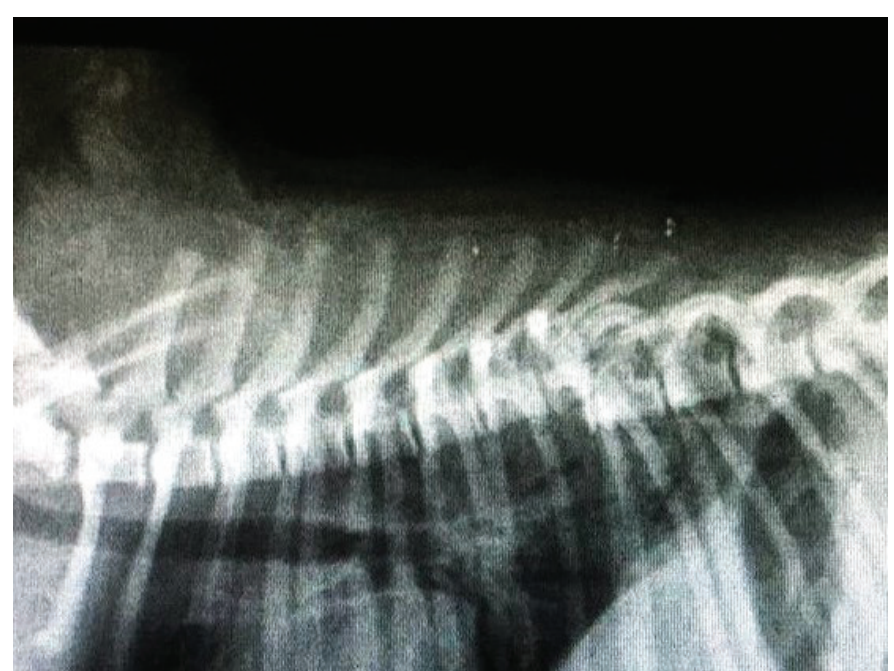

Fig.1. Radiografia laterolateral de cão após acidente automobilístico. Nota-se fratura vertebral em T8 e consequente subluxação vertebral.

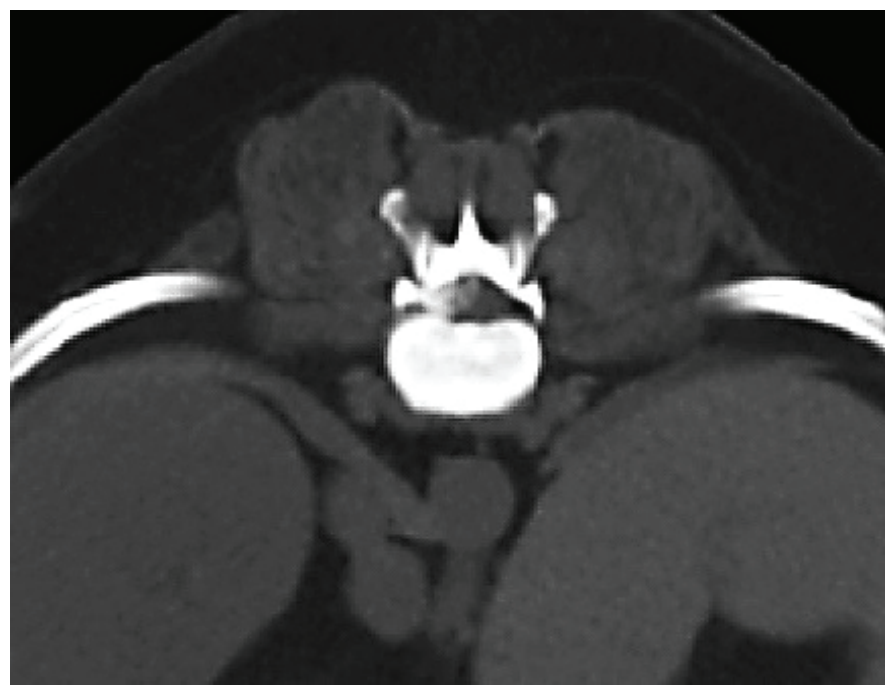

Fig.2. Tomografia computadorizada com corte transversal de cão. Nota-se material ocupando grande parte do canal vertebral com consequente compressão da medula espinhal.
Continence Society), adaptada para cães adultos. Os dados referentes ao estudo cistométrico, basearam-se nas análises das pressões vesical, abdominal e detrusora, em três períodos: 1 = avaliação pré-transplante, momento que o proprietário consentiu a participação do seu cão no estudo; 2 = primeira avaliação pós-transplante, 30 dias após dois transplantes de CTDAs e 3 = segunda avaliação pós-transplante, 60 dias após os dois transplantes de CTDAs.

A técnica de cistometria foi similar à usada por Goldstein \& Westropp (2005). Após o animal ser contido e mantido em decúbito lateral esquerdo, um cateter com duplo lúmen de 7Fr foi colocado de forma asséptica no interior da bexiga urinária do cão. Uma das aberturas do cateter esteve ligado ao transdutor de pressão da máquina, enquanto que a outra abertura foi utilizada para a administração de solução salina $0,9 \%$ na velocidade de $10-20 \mathrm{~mL} / \mathrm{min}$. Em seguida foi inserida uma sonda retal de $6 \mathrm{fr}$ com balonete na extremidade distal para aferição da pressão intrabdominal. Esta sonda foi inserida no ânus até o nível da sétima vértebra lombar e nos casos que havia a presença de fezes, estas foram manualmente removidas (Fig.3).

Isolamento, cultivo e viabilidade das CTDAs de cães. Quatro cachorras hígidas submetidas à ovarioisterectomia eletiva foram doadoras do tecido adiposo (TA) utilizado para a obtenção de células-tronco. Os proprietários assinaram termo de consentimento da doação do material biológico.

0 TA foi processado e as CTDAs foram isoladas utilizando o método de digestão enzimática. Brevemente, o TA foi lavado com solução salina fosfatada (PBS, Gibco ${ }^{\mathrm{TM}}$ Invitrogen, NY, USA) e feita uma digestão com $1 \mathrm{mg} / \mathrm{mL}$ de colagenase tipo I (Gibco ${ }^{\mathrm{TM}}$ Invitrogen, NY, USA) durante 30 minutos a $37^{\circ} \mathrm{C}$ sob constante agitação, seguido por filtração utilizando filtro de $100 \mu \mathrm{m}$ (BD FALCON ${ }^{\mathrm{TM}}$, BD Biosciences Discovery Labware, Bedford, USA). A suspensão celular foi centrifugada a $800 \mathrm{~g}$ por 10 minutos e os eritrócitos contaminantes foram removidos após a lise com um tampão pH 7,3 (Zuk et al. 2002). As células foram lavadas, filtradas novamente com filtro de $40 \mu \mathrm{m}$ (BD FALCON ${ }^{\mathrm{TM}}$, BD Biosciences Discovery Labware, Bedford, USA) e cultivadas numa densidade de $1 \times 10^{5}$ células $/ \mathrm{cm}^{2}$ em frascos de cultura com área de crescimento de $75 \mathrm{~cm}^{2}$ (TPP, Trasadingen, Switzerland) em meio DMEM-F12 (Gibco ${ }^{\mathrm{TM}}$ Invitrogen, NY, USA) suplementado com $15 \%$ de soro bovino fetal (SBF -Gibco ${ }^{\mathrm{TM}}$ Invitrogen, NY, USA) e $1 \%$ de

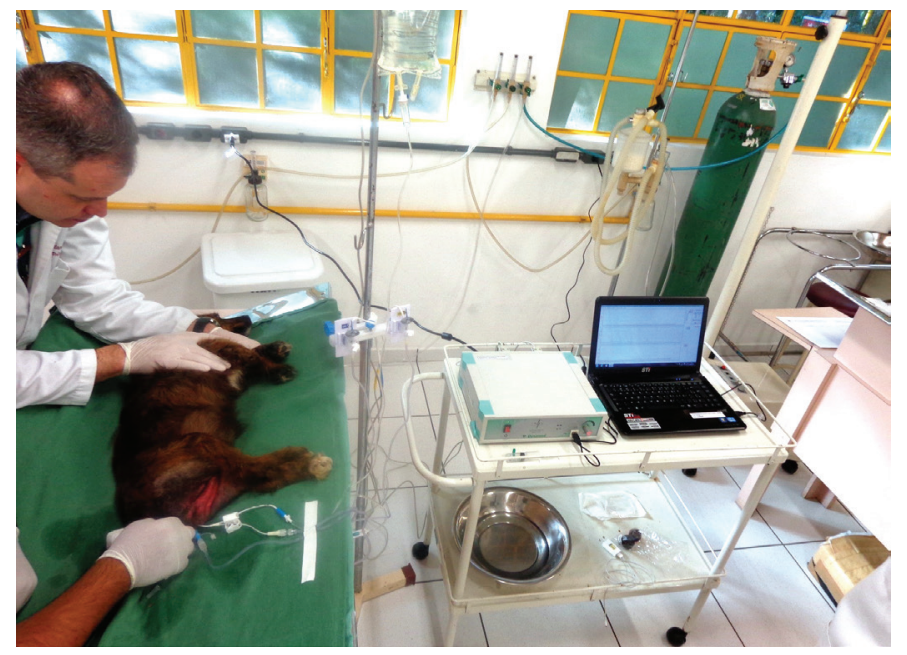

Fig.3. Cão com paraplegia e incontinência urinária, submetido à avaliação cistométrica. As sondas retal e uretral que estão inseridas no paciente estão ligadas à transdutores do aparelho de urodinâmica que está conectado ao notebook. 
penicilina (100 unidades $/ \mathrm{mL})$ e estreptomicina $(100 \mu \mathrm{g} / \mathrm{mL})\left(\mathrm{Gibco}^{\mathrm{TM}}\right.$ Invitrogen, NY, USA). As células foram mantidas em estufa com 5\% de tensão de $\mathrm{CO}_{2}, 37^{\circ} \mathrm{C}$ e $95 \%$ de umidade. 0 meio foi trocado quatro dias após o plaqueamento inicial. 0 meio de cultura foi substituído duas vezes por semana. Quando as culturas atingiram cerca de 80\%-90\% de confluência, as células foram dissociadas utilizando tripsina/EDTA 0,25\% (Invitrogen ${ }^{\mathrm{TM}}$, NY, USA) e replaqueadas (passagem 1). Para o transplante celular, foram utilizadas células entre a terceira e quinta passagem.

Previamente ao transplante, as células foram contadas em Câmara de Neubauer e foi realizada a avaliação da viabilidade celular utilizando o corante vital Azul de Tripan (Sigma Aldrich, USA). Cerca de $10 \mu \mathrm{l}$ do corante azul de tripan (Sigma Aldrich, USA), que cora as células não viáveis em azul, foi adicionado $50 \mu$ l de células. A avaliação foi feita em câmara de Neubauer.

Imunofenotipagem. Para avaliar a expressão de proteínas na superfície das CTDAs de cães, as quais são importantes para a caracterização das células que estão sendo transplantadas nos animais, foram utilizados os anticorpos CD45 FITC, CD44 Alexa fluor 488, CD90 PE, CD29 PE, CD34 PE, CD9 RPE, CD14 APC e CD8a PerCP (Quadro 1).

Para a marcação, as células foram lavadas com PBS (PBS, Gibco ${ }^{\mathrm{TM}}$ Invitrogen, NY, USA) e incubadas no escuro durante 30 minutos a temperatura ambiente com os anticorpos citados. Após a incubação as células foram lavadas com tampão de lavagem e ressuspendidas em $500 \mu \mathrm{L}$ de uma solução contendo $1 \%$ de formaldeído. Anticorpos isotípicos de camundongo IgG1 foram utilizados como controle (BD Pharmingen, CA, USA). Aproximadamente 100.000 células marcadas foram adquiridas pelo citômetro de fluxo FACS Calibur (Becton Dickinson, Franklin Lakes, USA) e analisadas por meio do software FlowJo (Flowjo, Ashland, USA).

Diferenciação celular. 0 potencial de diferenciação das CTDAs em P3, foi avaliado pela indução da diferenciação em adipócitos, osteoblastos e condrócitos, utilizando meios comerciais.

Diferenciação adipogênica e osteogênica. CTDAs foram plaqueadas em triplicata, em duas placas de 24 poços (TPP, Trasadingen, Switzerland) sobre lamínulas. As células foram incubadas em estufa a $37^{\circ} \mathrm{C}$, com $5 \%$ de $\mathrm{CO}_{2}$ até atingirem uma confluência de $80 \%$. Foi adicionado $300 \mu \mathrm{L}$ de meio comercial para as diferenciações em adipócitos e osteoblastos (LONZA, Walkersville, MD, USA). A troca de meio foi realizada três vezes por semana durante 21 dias. Após a diferenciação adipocítica, foi realizada a citoquímica com o corante Oil Red 0 para visualização dos vacúolos lipídicos (Sigma-Aldrich, St Louis, USA.). Brevemente, as células foram fixadas com Bouin (Biotec, Labmaster, Paraná, Brazil) durante 10 minutos a temperatura ambiente, lavadas duas vezes com etanol a $70 \% \mathrm{e}$ uma vez com água Mili-Q, e coradas com uma solução de $0.5 \%$ de Oil Red 0 (Sigma-Aldrich, St Louis, USA) durante uma hora. Para coloração do núcleo foi utilizado Hematoxilina (Biotec, Labmaster, Paraná, Brazil). Para a diferenciação osteogênica, após a fixação, foi adicionado às células Vermelho de Alizarina $S$ por 15 minutos (Fluka Chemie, Buchs, UK) a temperatura ambiente para avaliar a presença de cristais de cálcio.

Diferenciação condrogênica. Foi realizada a cultura em micromassa para a diferenciação condrogênica. Brevemente $5 \times 10^{5}$ células em $0,5 \mathrm{~mL}$ de meio de cultura foram centrifugadas a $300 \mathrm{~g}$ por 10 minutos, em um tubo cônico para formar um botão celular. Foi adicionado $500 \mu \mathrm{L}$ de meio de diferenciação condrogênica (LONZA, Walkersville, MD, USA) e as células foram cultivadas durante 21 dias. 0 meio foi trocado três vezes por semana. Após este período, o agregado celular foi fixado com $10 \%$ de formaldeído durante uma hora a temperatura ambiente, desidratado com diluições seriadas de etanol e emblocadas em blocos de parafina. Cortes de $4 \mu \mathrm{m}$ de espessura foram corados com solução de Azul de Toluidina (Sigma-Aldrich, St Louis, USA) para demonstrar a presença de mucopolissacarídeos na matriz intracelular.

As células controle, foram mantidas com meio IMDM suplementado com $15 \%$ de soro bovino fetal durante 21 dias.

Protocolo anestésico. A medicação pré-anestésica foi realizada por meio de injeção intramuscular de midazolan na dose de $0,2 \mathrm{mg} / \mathrm{kg}$. Em seguida, os cães foram submetidos a anestesia geral mediante injeção intravenosa de propofol na dose de $5 \mathrm{mg} / \mathrm{kg}$. A manutenção anestésica foi realizada com isofluorano a 3\% em circuito anestésico fechado, com oxigênio a $100 \%$.

Transplantes de CTDAs por punção lombar. Células entre P3 e P5, foram contadas em câmara de Neubauer e foram transplantadas, $12 \times 10^{6}$ CTDAs foram injetadas por punção lombar no sétimo e décimo quarto dias após a primeira avaliação cistométrica. As CTDAs foram diluídas em $100 \mu \mathrm{L}$ de meio de cultura e injetadas com seringa de Hamilton e agulha por punção lombar no espaço intradural, confirmada pela pressão de líquor no centro da agulha. A cada minuto, $10 \mu \mathrm{L}$ de solução foi injetada, e após a injeção dos $100 \mu \mathrm{L}$, a agulha foi mantida no espaço intradural durante cinco minutos para impedir qualquer refluxo (Fig.4).

\section{RESULTADOS}

Dos 11 cães participantes do estudo, 63,63\% (7/11) dos cães eram fêmeas sem raça definida (SRD), com média de peso de $10,02 \mathrm{~kg}$ e tempo de lesão de 12,6 meses. Os exames laboratoriais antes dos transplantes das CTDAs estavam dentro da normalidade, conforme valores de referência citados por Thrall (2015). Três animais $(27,27 \%)$ desenvolveram cistite bacteriana 30 dias após os dois transplantes. As cistites bacterianas são frequentes em cães paraplégicos e incontinentes e a urocultura revelou a presença de Escherichia coli $(66,67 \%)$ e

Quadro 1. Lista de anticorpos marcadores de superfície usados em citometria de fluxo

\begin{tabular}{|c|c|c|c|c|}
\hline Marcador de superfície celular & Reatividade de espécies & Clonalidade & Fonte & Catálogo \\
\hline CD45 - FITC & Canine & Monoclonal & eBioscience & $11-5450-42$ \\
\hline CD44 - Alexa fluor 488 & Dog & Monoclonal & AbD Serotec & MCA1041A488 \\
\hline CD90 - PE & Human. Tested in development: dog & Monoclonal & BD Pharmingen & 555596 \\
\hline CD29 - PE & Canine & Monoclonal & Abcam & ab64629 \\
\hline CD34 - PE & Canine & Monoclonal & eBioscience & $12-0340-42$ \\
\hline CD9 - RPE & Dog & Monoclonal & AbD Serotec & MCA469PET \\
\hline CD14 - APC & Human. Tested in development: dog & Monoclonal & BD Pharmingen & 555399 \\
\hline CD8a - PerCP & Canine & Monoclonal & eBioscience & $46-5080-42$ \\
\hline
\end{tabular}




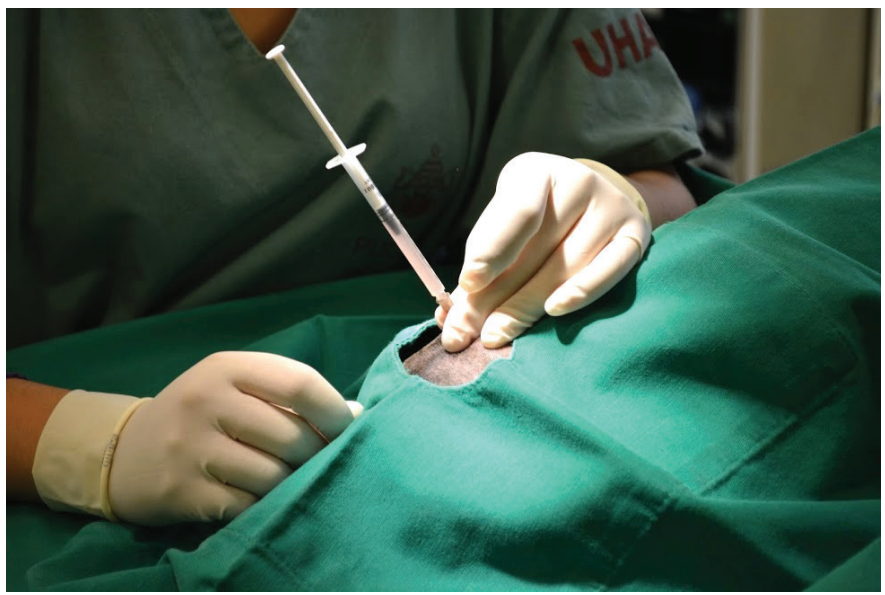

Fig.4. Transplante de $12 \times 10^{6}$ CTDA diluídas em $100 \mu \mathrm{L}$ de meio de cultura, injetadas por punção lombar no espaço intradural.

Staphylococcus aureus (33,33\%), enquanto que o antibiograma mostrou sensibilidade à Enrofloxacina $(66,67 \%)$ e Ceftriaxona $(33,33 \%)$. Estes animais receberam o tratamento adequado.

A porcentagem de cães que apresentavam fratura vertebral com subluxação vertebral foi de 81,81\% (9/11) e o restante extrusão discal comprovada tomograficamente. Nenhum dos pacientes foi submetido à estabilização vertebral ou descompressão medular, antes ou após os transplantes de CTDAs.

Conforme a escala usada por Penning et al. (2006) para grau de lesão na avaliação pré-transplante, a maioria $(8 / 11,72,73 \%)$ dos cães apresentavam Grau V, seguido de Grau II $(2 / 11,18,18 \%)$ e Grau IV (1/11, 9,09\%). No teste de sensibilidade 18,18\% $(2 / 11)$ apresentaram grau 1 de sensibilidade - presença de dores superficial e profunda; 9,09\% (1/11) apresentou grau 2 de sensibilidade - presença de dor superficial e ausência de dor profunda, enquanto $72,73 \%$ (8/11) apresentaram grau 3 de sensibilidade (ausência de dor superficial e profunda (Sharp \& Wheeler 2005, Dewey et al. 2016). Não foram observadas alterações de resultados nas avaliações sensitivas e motoras pré e pós-transplantes.

Por meio de avaliação cistométrica foi observado que um cão com alteração da complacência vesical associada à contração detrusora isolada e associada à perda ao final do enchimento vesical, recuperou a condição de normalidade 30 dias após os dois transplantes de CTDAs, entretanto, 60 dias após os transplantes apresentou baixa complacência, contrações detrusoras de alta amplitude com perda urinária associada. Nos demais cães não foram observadas mudanças nas avaliações cistométricas nos períodos pré, 30 e 60 dias pós transplantes (Quadro 2) e a maioria dos animais $(6 / 11,54,54 \%$ ) apresentou alteração da complacência vesical com hiperatividade detrusora, porém sem perdas urinárias. Também houve o relato de alguns proprietários que seus animais tiveram melhora clínica no que se refere à procura de grama para urinar e diminuição do gotejamento urinário.

0 volume médio de TA obtido foi de $65 \mathrm{~mL}$ e o número médio de células após o isolamento foi de $25,75 \times 10^{6}$ células. As células em cultivo apresentaram uma rápida expansão celular, morfologia fibroblastoide (Fig.5) e a média de viabilidade celular antes do transplante foi de $94,91 \%$. A expressão dos

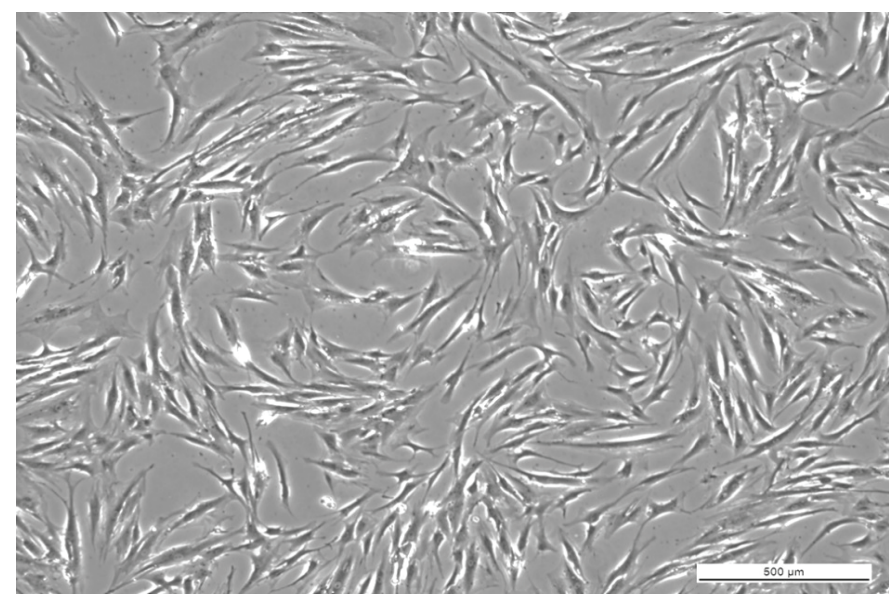

Fig.5. Células-tronco de tecido adiposo de cão em processo de cultivo, terceira passagem. $0 b j .5 \mathrm{x}$.

Quadro 2. Resultados dos exames cistométricos em cães com lesão toracolombar crônica, comparados ao grupo controle, composto por animais hígidos, resultados expressos em $\mathrm{cm} \mathrm{H}_{2} \mathrm{O}(\mathrm{n}=11)$

\begin{tabular}{lccc}
\hline & Pressão vesical & $\begin{array}{c}\text { Pressão } \\
\text { abdominal }\end{array}$ & $\begin{array}{c}\text { Pressão } \\
\text { detrusora }\end{array}$ \\
\hline $\begin{array}{l}\text { Pré-transplante } \\
\text { 30 dias após }\end{array}$ & $6,18 \pm 2,5$ & $-5,09 \pm 10,5$ & $11,18 \pm 17,74$ \\
transplante & $8,45 \pm 2,9$ & $-3,27 \pm 6,03$ & $11,72 \pm 14,05$ \\
$\begin{array}{l}\text { 6 dias após } \\
\text { transplante }\end{array}$ & $11,72 \pm 3,4$ & $-3,27 \pm 7,24$ & $15,0 \pm 13,63$ \\
Grupo controle & $29,25 \pm 2,34$ & $3,15 \pm 0,25$ & $23,75 \pm 1,9$
\end{tabular}

Os valores estão expressos em média \pm erro padrão da média; teste ANOVA de uma via de medidas repetitivas, seguido pelo pós-teste de Tukey, teste de normalidade de Kolmogorov-Smirnov.

antígenos de superfície nas CTDAs foi avaliada por citometria de fluxo e foram obtidos os seguintes resultados: CD29 (99,2\%), CD44 (92,9\%), CD9 (92,5\%), CD8a (41,8\%), CD14 (1,39\%), CD45 (3,11\%), CD34 (5,07\%) e CD90 (36,1\%) (Fig.6).

A diferenciação em adipócitos, osteoblastos e condrócitos foi avaliada por citoquímica. Na diferenciação adipogênica foram visualizados vacúolos lipídicos no interior das células induzidas a diferenciação. Nas células tratadas com meio de diferenciação osteogênica foi observada a presença de cristais de cálcio nas células. Nos ensaios de diferenciação condrogênica, as CTDAs formaram agregados que cresceram em suspenção em cultura. Houve a produção de moléculas de matriz extracelular, como proteoglicanas sulfatadas na matriz cartilaginosa. Foram observadas a presença de células cuboidais e lacunas ao redor dos condrócitos jovens. As células controle, não demonstraram diferenciação espontânea após 21 dias de cultivo (Fig.7).

\section{DISCUSSÃO}

A International Society for Cellular Therapy (ISCT) estabeleceu critérios mínimos para definir uma população de CTMs humanas, como a morfologia fibroblastoide, a expressão de marcadores de superfície e a diferenciação celular em 


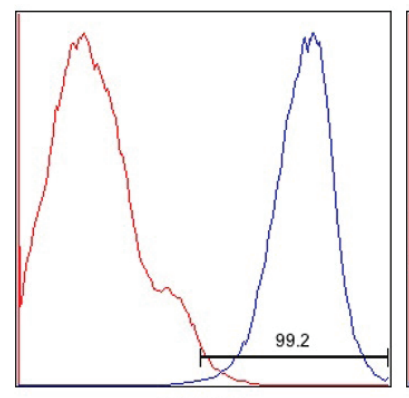

CD29+

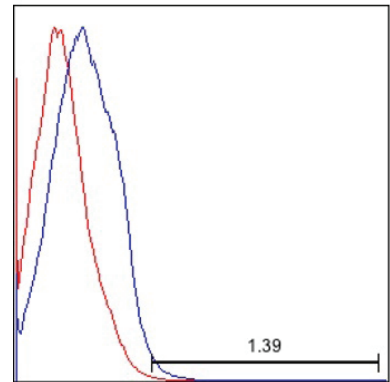

CD14+

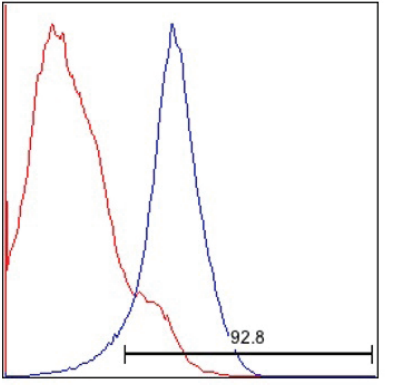

CD44+

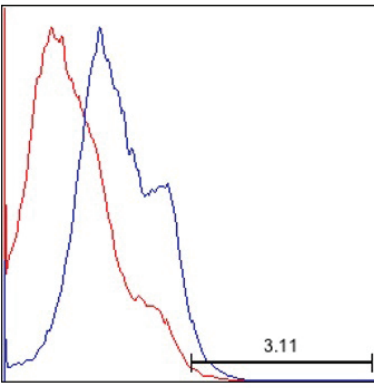

CD45+

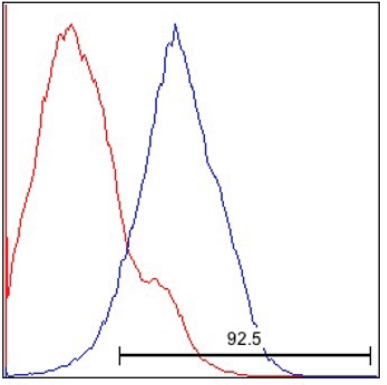

CD9+

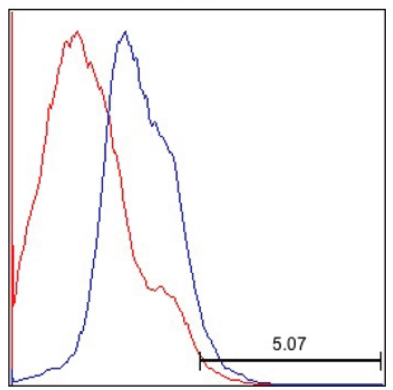

CD34+

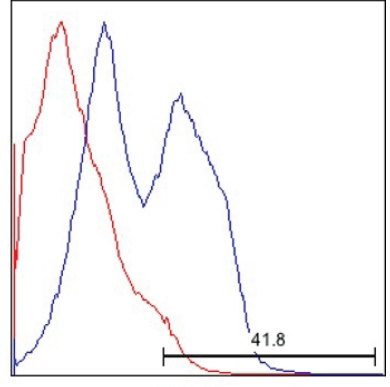

CD8a+

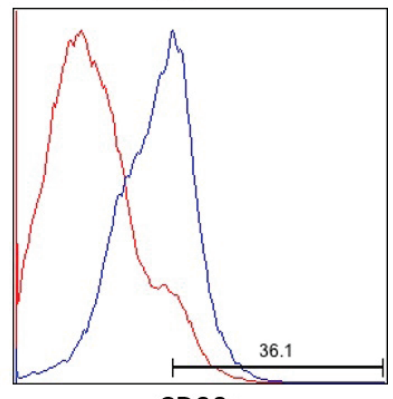

CD90+

Fig.6. Análise imunofenotípica por citometria de fluxo. Os histogramas azuis indicam a porcentagem da população positiva para cada anticorpo enquanto os histogramas vermelhos indicam o controle isotípico dos anticorpos.

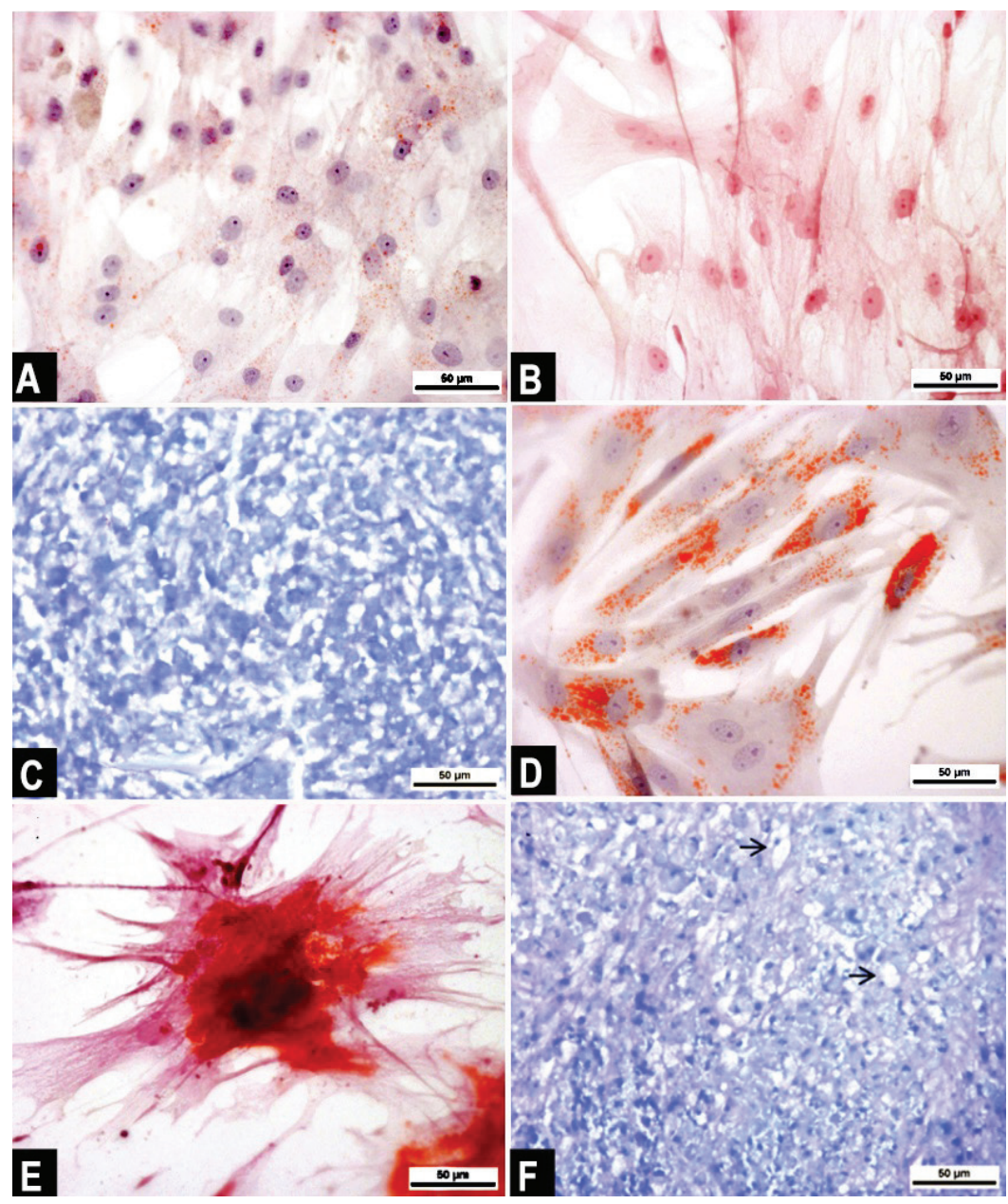

Fig.7. Diferenciação in vitro das CTDAs após 21 dias de cultivo. (A-C) Células controle. (D) Células diferenciadas em adipócitos, demonstrando a presença de vacúolos lipídicos no interior das células, corados com Oil Red O. (E) Células diferenciadas em osteoblastos. Presença de depósito de cálcio corado com Vermelho de Alizarina S. (F) Presença de vacúolos ao redor de condrócitos jovens. Obj.40x. 
três linhagens diferentes (Dominici et al. 2006). Em relação aos marcadores de superfície, devido a falta de marcadores espécie-específico, não foi possível utilizar todos os anticorpos sugeridos pela ISCT (positividade para os marcadores CD105, CD73 e CD90 e negatividade para CD45, CD34, CD14 ou CD11b, CD79a ou CD19 e HLA de classe II). Neste estudo a expressão do marcador CD90 foi de 36,1\%, apesar da forte expressão em células humanas. Takemitsu et al. (2012) e Screven et al. (2014) obtiveram resultado semelhante em amostras de células-tronco mesenquimais obtidas de tecido adiposo e medula de cães. Também foi observado que as CTDAs apresentaram perfil imunofenotípico positivo para os marcadores CD29 e CD44, o que está de acordo com outros trabalhos (Vieira et al. 2010, Kang et al. 2012).

Em relação aos antígenos CD14 e CD45, foi vericado uma baixa expressão. Blecker et al. 2017 e Escalhão et al., 2017 também avaliaram os marcadores de superfície em amostras de tecido adiposo de cães e observaram baixa ou nenhuma expressão dos antígenos CD14 e CD45. A expressão dos marcadores de superfície varia não somente entre as células de diferentes espécies mas também entre diferentes indivíduos da mesma espécie (Blecker et al. 2017).

Também de acordo com os critérios estabelecidos para definição de células-tronco mesenquimais, as células-tronco de cães utilizadas neste estudo, demonstraram o potencial de diferenciação em adipócitos, osteoblastos e condrócitos. Outros estudos utilizando CTDAs também relatam a diferenciação nestas três linhagens celulares (Neupane et al. 2008, Escalhão et al. 2017).

Observou-se no presente estudo que as CTDAs de cães apresentaram propriedades in vitro bastante semelhantes às observadas em humanos (Romanov et al. 2005). 0 número de células usado foi similar ao usado por Jung et al. (2009), que também usaram CTDA alogênicas, e que diferente desse estudo, observaram melhora clínica dos cães, entretanto, similar a Lim et al. (2007), transplantaram células em cães com lesão aguda após compressão medular.

O estudo realizado por Lim et al. (2007) com cães cuja medula espinhal foi lesionada por meio de compressão com balão de embolectomia, e foram tratados com células-tronco do cordão umbilical, mostrou melhora significativa em escores comportamentais. No entanto a lesão causada nesse estudo apresentava caráter agudo, de provável resolução espontânea, pelo menos parcialmente. Todos os casos selecionados no presente estudo apresentavam lesão crônica, com período mínimo de seis meses e máximo de dois anos, e provável cicatriz glial.

Kurozumi et al. (2004), Lu et al. (2005) e Quertainmont et al. (2012), demonstraram que as CTDAs são capazes de secretar fatores de crescimento e citocinas, como o fator de crescimento neural (NGF), fator neurotrófico derivado do cérebro (BDNF) e fator de crescimento endotelial vascular (VEGF), além do aumento da expressão de citocinas anti-inflamatórias como IFN-y e IL-10. Estas citocinas e fatores tróficos podem ter um efeito benéfico após a lesão espinhal sobre a reparação e reorganização das conexões neuronais, na indução de regeneração, no estímulo a neurogênese, no crescimento axonal, na redução da resposta inflamatória e na proteção do tecido, todavia tais mecanismos são pouco duradouros, provavelmente poucas semanas, e possivelmente não tenham ação sobre cicatriz glial, a qual provavelmente estava presente em todos os cães pertencentes a este estudo.

0 processo regenerativo de danos sofridos ao sistema nervoso central (SNC), e em especial a medula espinhal, apresenta alguns fatores limitantes, tais como a capacidade limitada do SNC em repor as células danificadas (Johansson et al. 1999) e a produção de inibidores do crescimento dos axônios associados com mielina e a formação da cicatriz glial (Olson 2002), que é constituída predominantemente de astrócitos reativos, micróglia/macrófagos e moléculas da matriz extracelular, especialmente de sulfato de condroitina proteoglicana (Rolls et al. 2008).

Apesar de apontada como a grande vilã da regeneração das lesões medulares, estudos demonstram vários efeitos benéficos desta cicatriz nas primeiras semanas após a lesão medular (Rolls et al. 2008). A eliminação dos astrócitos reativos, ou a prevenção da migração dos mesmos após a lesão medular resulta em falhas no processo de recuperação da barreira hemato-encefálica, acompanhada por infiltração celular massiva e aumento da perda de neurônios e oligodendrócitos (Okada et al. 2006).

Os efeitos inibitórios do tecido cicatricial são considerados como o principal empecilho a regeneração do tecido nervoso. Vários estudos demonstram a utilização de substâncias e enzimas que eliminam ou reorganizam a cicatriz glial e também com ressecção cirúrgica da cicatriz glial, onde se tem destacado o uso de condrotinase $\mathrm{ABC}$, uma substância que atua principalmente na eliminação da cicatriz glial, em qualquer época da sua formação (Jones et al. 2003, Rolls et al. 2008, Shields et al. 2008, Rasouli et al. 2009, Tom et al. 2009).

Neste estudo optou-se pelo transplante por punção lombar no espaço intradural conforme estudos de Bakshi et al. (2004) e Kumar et al. (2009). Villanova Junior (2013) e Fracaro et al. (2014) utilizando um modelo de lesão medular por compressão em ratos Wistar e transplante de CTDAs humanas por punção lombar, observaram a sobrevivência e migração destas células para a área lesionada, sendo encontradas inclusive no parênquima medular (Fracaro et al. 2014). Por meio de exame neurológico, foi demonstrado que não houve piora funcional nos animais, o que indica que o transplante de CTDAs foi seguro.

O homing das CTDAs devido a presença principalmente de citocinas inflamatórias, é de grande importância para a resposta clínica, pois injeções diretamente no tecido da medula espinhal, podem causar danos adicionais (Bakshi et al. 2004, Spaeth et al. 2008). Entretanto, devido ao longo período pós-lesão, provavelmente a cicatriz glial e ausência de inflamação, impossibilitaram o homing das CTDAs para o tecido neural, impedindo sua ação parácrina ou de diferenciação celular. Apenas um cão apresentou melhora cistométrica, e ela foi pouco duradoura, passados 60 dias pós transplante, o estado miccional retornou ao observado no período pré transplante, indicando a necessidade de outras infusões de células para melhora do quadro. Além disso, é preciso considerar que a incontinência por um longo período, gera maior grau de colagenização da bexiga urinária, o que impede boa dilatação e adequada complacência (Maia et al. 2006, D’Ancona \& Moro 2015).

Neste estudo observou-se discreta melhora da funcionalidade vesical, porém sem significância estatística, resultados também 
observados por Pal et al. (2010), Carvalho (2011) e Kaminski (2011) com células autólogas.

Animais com lesões graves, com paraplegia, incontinência e perda nociceptiva e com período longo de morbidez, com média superior a um ano, não apresentaram melhora clínica quando submetidos ao transplante de CTDAs no espaço intradural. A regeneração da lesão da medula espinhal é limitada por vários fatores, incluindo a perda significativa de neurônios, destruição axonal e liberação na cicatriz de moléculas inibidoras de crescimento tais como Nogo, glicoproteína à base de mielina, glicoproteína de mielina de oligidendrócito e tenascina, que são liberadas por oligodendrócitos danificados (Willerth \& Sakiyama-Elbert 2008, Lee et al. 2010, Wright et al. 2011, Sharma et al. 2012). Provavelmente o principal impedimento da regeneração é a formação de cicatriz glial no local da lesão em medulas espinhais cronicamente feridas. Portanto, as lesões crônicas da medula espinhal requerem diferentes estratégias para o tratamento, que em conjunto, poderiam fornecer resultados positivos (Karimi-Abdolrezaee et al. 2010, Lee et al. 2015).

Lee et al. (2015) observam melhora clínica de cães com lesões medulares crônicas submetidos ao transplante de CTDAs, entretanto, o tempo de lesão em todos os animais avaliados foi de três semanas. Sarmento et al. (2014) também obtiveram efetividade do transplante celular em cães com lesões medulares toracolombares com período de lesão superior a 60 dias, porém, usaram células-tronco de medula óssea fetal, associadas a descompressão cirúrgica e fisioterapia.

O uso de cães com lesões ou doenças preexistentes é uma opção muito interessante para desenvolver novas estratégias em medicina regenerativa, uma vez que a maioria das doenças caninas são estruturalmente e funcionalmente bastante semelhantes as descritas em seres humanos (Penha et al. 2014, McMahill et al. 2015). Este estudo avaliou a segurança e eficácia do uso das CTDAs alogênicas em cães com lesão medular toracolombar crônica provocada por trauma ou doença do disco intervertebral não induzidas.

Cães portadores de lesões medulares que apresentam incontinência urinária, seja pela presença de esfíncteres uretrais flácidos ou espásticos, desenvolverão cistite bacterina, mesmo havendo pelos proprietários, esvaziamentos vesicais manuais regulares (Dewey \& Costa 2016), no presente estudo foram realizados exames laboratoriais pré-transplantes, visando maior segurança durante as anestesias gerais para a realização dos transplantes de CTDA, bem como para que não houvesse influência da cistite bacteriana no exame cistométrico (Goldstein \& Westropp 2005, D’Ancona \& Moro 2015). Muitos animais não fizeram parte do estudo por justamente apesentarem cistites bacterianas recorrentes de difícil tratamento. Observamos que em apenas dois cães ocorreu cistite bacteriana na avaliação realizada 30 dias após os dois transplantes de CTDA. Os animais estavam assintomáticos e foi de fácil resolução após urocultura e antibiograma.

A maioria dos animais não tinham raça definida, e eram de proprietários de baixo poder aquisitivo, moradores de bairros de periferia, que buscam assistencialismo em hospitais veterinários escola, como o local do presente estudo. De todos os animais avaliados, apenas dois apresentavam avaliações tomográficas, e o aparelho não está disponível no local do estudo, entretanto ao oferecermos nova análise de forma gratuita, em hospital veterinário privado, ambos os proprietários não aceitaram nova avaliação por considerar risco de morte desnecessário pela nova submissão de anestesia geral, afinal não haviam observado melhora com significância clínica e não estava programado novo transplante de CTDA.

Em nenhum animal com fratura vertebral e consequente subluxação foi realizada avaliação tomográfica pré-transplante, e a realização deste exame de neuroimagem nos períodos pós-transplantes, seria muito custoso, pois seria em nove animais, e principalmente, não ofereceria a possibilidade de comparação dos períodos pré e pós-transplantes. Os autores do presente estudo, reconhecem que atualmente o melhor exame de neuroimagem para avaliação do parênquima medular é a imagem de ressonância magnética, conforme preconizado por Nishida et al. $(2011,2012)$, Tamura et al. (2012), Chung et al. (2013) e Hech \& Costa (2016), entretanto este exame para animais não está disponível na cidade e em regiões próximas de onde foi realizado o presente estudo.

Intervenções cirúrgicas estabilizadoras ou descompressivas também não foram realizadas, pois o objetivo era avaliar os efeitos dos transplantes de CTDA sem influência da intervenção cirúrgica e de métodos convencionais como fisioterapia, acupuntura ou ozonioterapia, instituíd os em cães com lesões crônicas, aonde é difícil prever os resultados da terapia celular. E é neste aspecto que observamos que a associação poderia ser o diferencial, Feitosa (2011) e Prado (2016) observaram resultados favoráveis quando fizeram o uso de células-tronco mesenquimais associado à intervenção cirúrgica.

A imunização com vacina recombinate que atua no sítio de ligação dos inibidores de crescimento axonal (Nogo A, AMG e OMP) nas células axonais (Yu et al. 2007) e mesmo o tratamento com anticorpos anti Nogo A (Freund et al. 2009) parecem ser o futuro de terapias na lesão medular. 0 conjunto dessas terapias associada à terapia com células-tronco podem representar uma esperança bastante realista na busca de cura de lesões medulares (Feitosa 2011).

\section{CONCLUSÃO}

O transplante das CTDAs no espaço intradural para o tratamento de cães com lesão medular crônica mostrou ser um procedimento seguro, pois não foram observados efeitos adversos ou piora funcional. Houve uma melhora discreta da funcionalidade vesical, porém não foi observada melhora na sensibilidade e redução do grau de lesão.

Agradecimentos.- Agradecemos às pesquisadoras Alexandra Cristina Senegaglia e Lidiane Maria Boldrini Leite pelo auxílio na realização da citometria de fluxo. Ao Felipe Yukio Ishikawa pelo auxílio no cultivo das células e pelas fotografias.

\section{REFERÊNCIAS}

Antonic A., Sena E.S., Lees J.S., Wills T.E., Skeers P., Batchelor P.E., Macleod M.R. \& Howells D.W. 2013. Stem cell transplantation in traumatic spinal cord injury: a systematic review and meta-analysis of animal studies. J. Plos Biol. 11(12):e1001738. <http://dx.doi.org/10.1371/journal. pbio.1001738><PMid:24358022>

Bakshi A., Hunter C., Swanger S., Lepore A. \& Fischer I. 2004. Minimally invasive delivery of stem cells for spinal cord injury: advantages of the lumbar puncture technique. J. Neurosci. 1(3):330-337. <PMid:15478372>

Blecker D., Elashry M.I., Heimann M., Wenisch S. \& Arnhold S. 2017. New insights into the neural differentiation potential of canine adipose tissue- 
derived mesenchymal stem cells. Anat. Histol. Embryol. 46(3):304-315. <http://dx.doi.org/10.1111/ahe.12270 > <PMid:28401575>

Carvalho P.H. 2011. Avaliação neurológica e histológica de lesão compressiva da medula espinhal de ratos Wistar, tratados com células-tronco mesenquimais. Dissertação de Mestrado. Disponível em <http://locus. ufv.br/handle/123456789/5059> Acesso em 18 abr. 2017.

Chung W.H., Park S.A., Lee J.H., Chung D.J., Yang W.J., Kang E.H., Choi C.B., Chang H.S., Kim D.H., Hwang S.H., Han H. \& Kim H.Y. 2013. Percutaneous transplantation of human umbilical cord-derived mesenchymal stem cells in a dog suspected to have fibrocartilaginous embolic myelopathy. J. Vet. Sci. 14(4):495-497. <http://dx.doi.org/10.4142/jvs.2013.14.4.495> <PMid:23820160>

D’Ancona C.A.L. \& Moro J.C. 2015. Cistometria, p.53-60. In: Ibid. (Eds), Avaliação Urodinâmica e suas Aplicações Clínicas. $5^{\mathrm{a}}$ ed. Atheneu, São Paulo.

Dewey C.W. \& Fossum T.W. 2013. Surgery of the thoracolumbar spine, p.15141528. In: Ibid. (Eds), Small Animal Surgery. 41st ed. Elsevier, Missouri.

Dewey C.W. \& Costa R.C. 2016. Myelopathies: disorders of the spinal cord, p.329-404. In: Ibid. (Eds), Practical Guide to Canine and Feline Neurology. 13th ed. John Wiley \& Sons, Iowa.

Dewey C.W., Costa R.C. \& Thomas W.B. 2016. Performing the neurologic examination, p.9-28. In: Ibid. (Eds), Practical Guide to Canine and Feline Neurology. 2nd ed. John Wiley \& Sons, Iowa.

Dominici M., Le Blanc K., Mueller I., Slaper-Cortenbach I., Marini F., Krause D., Deans R., Keating A., Prockop Dj. \& Horwitz E. 2006. Minimal criteria for defining multipotent mesenchymal stromal cells: the International Society for Cellular Therapy position statement. Cytotherapy 8(4):315-317. <http://dx.doi.org/10.1080/14653240600855905> <PMid:16923606>

Donnelly E.M., Lamanna J. \& Boulis N.M. 2012. Stem cell therapy for the spinal cord. Stem Cell Res. Ther. 3(4):24. <http://dx.doi.org/10.1186/ scrt115><PMid:22776143>

Doorn J., Moll G., Le Blanc K., Van Blitterswijk C. \& De Boer J. 2012. Therapeutic applications of mesenchymal stromal cells: paracrine effects and potential improvements. Tissue Eng. B 18(2):101-115. <http://dx.doi.org/10.1089/ ten.teb.2011.0488><PMid:21995703>

Escalhão C.C.M., Ramos I.P., Hochman-Mendez C., Brunswick T.H.K., Souza S.A.L., Gutfilen B., Goldenberg R.C.S. \& Sampaio T.C. 2017. Safety of allogeneic canine adipose tissue-derived mesenchymal stem cell intraspinal transplantation in dogs with chronic spinal cord injury. Stem Cells Int. 2017:3053759. <http://dx.doi.org/10.1155/2017/3053759><PMid:28611846>

Feitosa M.L.T. 2011. Terapia celular com células-tronco em coelhos com lesão medular induzida e em cães com lesão medular crônica espontânea. Tese de Doutorado. <http://dx.doi.org/10.11606/T.10.2011.tde-03052012-143409>

Fernández V.L. \& Bernardini M. 2010. Neurologia em Cães e Gatos. MedVet, Universidade Metodista de São Paulo, São Paulo. 445p.

Fine A. 1994. Transplantation of fetal cells and tissue: an overview. Can. Med. Assoc. J. 151(9):1261-1268. <PMid:7954174>

Fitzmaurice S.N. 2011. Neurologia em Pequenos Animais. Elsevier, Rio de Janeiro, p.181-183.

Fletcher D.J., Dewey C.W. \& Costa R.C. 2016. Practical Guide to Canine and Feline Neurology. Vol. 4. Wiley-Blackwel, Iowa, p.481-494.

Forner S. 2011. Envolvimento dos receptores b1 e b2 para as cininas na hiperatividade da bexiga urinária induzida por lesão medular em ratos. Dissertação de Mestrado. Disponível em <http://repositorio.ufsc.br/xmlui/ handle/123456789/95840> Acesso em 18 out. 2017.

Fracaro L., Villanova Junior J.A., Silva A.J., Barchiki F., Moura S.A.B., Pimpão C.T., Dominguez A.C., Dittrich R.L., Rebelatto C.K. \& Brofman P.R.S. 2014. Transplante de células-tronco em ratos submetidos à lesão medular compressiva, com e sem tratamento com corticoide. Revta Acad., Ciênc. Agrár. Ambient. PUCPR 12(Supl.1):34-35.
Freund P., Schmidlin E., Wannier T., Bloch J., Mir A., Schwab M.E. \& Rouiller E.M. 2009. Anti-nogo-A antibody treatment promotes recovery of manual dexterity after unilateral cervical lesion in adult primates-re-examination and extension of behavioral data. Eur. J. Neurosci. 29(5):983-996. <http:// dx.doi.org/10.1111/j.1460-9568.2009.06642.x><PMid:19291225>

Goldstein R.E. \& Westropp J.L. 2005. Urodinamyc testing in the diagnosis of small animal micturition disorders. Clin. Tech. Small Anim. Pract. 20(1):6572.<http://dx.doi.org/10.1053/j.ctsap.2004.12.009><PMid:15822532>

Granger N., Franklin R.J. \& Jeffery N.D. 2014. Cell therapy for spinal cord injuries: what is really going on? Neuroscientist 20(6):623-638. <http:// dx.doi.org/10.1177/1073858413514635> <PMid:24415275>

Green J., Bosco E. \& Tello L.H. 2008. Trauma de medula espinhal, p.165-176. In: Ibid. (Eds), Trauma em Cães e Gatos. MedVet, Universidade Metododista de São Paulo, São Paulo.

Hech S. \& Costa R.C. 2016. Principles and application of magnetic ressonance imaging: brain and spine, p.87-140. In: Ibid. (Eds), Practical Guide to Canine and Feline Neurology. 6th ed. John Wiley \& Sons, Iowa.

Hoffman A.M. \& Dow S.W. 2016. Concise review: stem cells trials using comparison animal diseases models. Stem Cells 34(7):1709-1729. <http:// dx.doi.org/10.1002/stem.2377> <PMid:27066769>

Johansson C.B., Momma S., Clarke D.L., Risling M., Lendahl U. \& Frisen J. 1999. Identification of a neural stem cell in the adult mammalian central nervous system. Cell 96(1):25-34. <http://dx.doi.org/10.1016/S00928674(00)80956-3><PMid:9989494>

Jones L.L., Margolis R.U. \& Tuszynski M.H. 2003. The chondroitin sulfate proteoglycans neurocan, brevican, phosphacan, and versican are differentially regulated following spinal cord injury. Exp. Neurol. 182(2):399-411. <http://dx.doi.org/10.1016/S0014-4886(03)00087-6><PMid:12895450>

Jung D.I., Ha J., Kang B.T., Kim J.W., Quan F.S., Lee J.H., Woo E.J. \& Park H.M. 2009. A comparison of autologous and allogenic bone marrow-derived mesenchymal stem cell transplantation in canine spinal cord injury. J. Neurosci. 285(1/2):67-77. <PMid:19555980>

Kadiyala S., Young R.G., Thiede M.A. \& Bruder S.P. 1997. Culture expanded canine mesenchymal stem cells possess osteochondrogenic potential in vivo and in vitro. Cell Transplant. 6(2):125-134. <PMid:9142444>

Kaminski E.L. 2011. Transplante de células mononucleares da medula óssea em um modelo experimental de lesão da medula espinhal. Dissertação de Mestrado. Disponível em <http://hdl.handle.net/10923/4462> Acesso em 18 out. 2017.

Kang E.S., Ha K.Y. \& Kim Y.H. 2012. Fate of transplanted bone marrow derived mesenchymal stem cells following spinal cord injury in rats by transplantation routes. J. Korean Med. Sci. 27(6):586-593. <http://dx.doi. org/10.3346/jkms.2012.27.6.586><PMid:22690088>

Kang S.K., Shin M.J., Jung J.S., Kim Y.G. \& Kim C.H. 2006. Autologous adipose tissue-derived stromal cells for treatment of spinal cord injury. Stem Cells Dev. 15(4):583-594.<http://dx.doi.org/10.1089/scd.2006.15.583> <PMid:16978061>

Karimi-Abdolrezaee S., Eftekharpour E., Wang J., Schut D. \& Fehlings M.G. 2010. Synergistic effects of transplanted adult neural stem/progenitor cells, chondroitinase, and growth factors promote functional repair and plasticity of the chronically injured spinal cord. J. Neurosci. 30(5):1657-1676. <http://dx.doi.org/10.1523/JNEUROSCI.3111-09.2010><PMid:20130176>

Kopen G.C., Prockop D.J. \& Phinney D.G. 1999. Marrowstromal cells migrate throughout forebrain and cerebellum, and they differentiate into astrocytes after injection into neonatal mouse brains. Proc. Natl Acad. Sci. 96(19):1071110716. <http://dx.doi.org/10.1073/pnas.96.19.10711><PMid:10485891>

Kumar A.A., Kumar S.R., Narayanan R., Arul K. \& Baskaran M. 2009. Autologous bone marrow derived mononuclear cell therapy for spinal cord injury: a phase I/II clinical safety and primary efficacy data. Exp. Clin. Transplant. 7(4):241-248. <PMid:20353375> 
Kurozumi K., Nakamura K., Tamiya T., Kawano Y., Kobune M., Hirai S., Uchida H., Sasaki K., Ito Y., Kato K., Honmou O., Houkin K., Date I. \& Hamada H. 2004. BDNF gene-modified mesenchymal stem cells promote functional recovery and reduce infarct size in the rat middle cerebral artery occlusion model. Mol. Ther. 9(2):189-197.<http://dx.doi.org/10.1016/j.ymthe.2003.10.012> $<$ PMid:14759803>

Lee J.H., Chung W.H., Kang E.H., Chung D.J., Choi C.B., Chang H.S., Lee J.H., Hwang S.H., Han H., Choe B.Y. \& Kim H.Y. 2011. Schwann cell-like remyelination following transplantation of human umbilical cord blood (hUCB)-derived mesenchymal stem cells in dogs with acute spinal cord injury. J. Neurological Sci. 300(1-2):86-96. <http://dx.doi.org/10.1016/j. jns.2010.09.025><PMid:21071039>

Lee J.S., Hong J.M., Moon G.J., Lee P.H., Ahn Y.H. \& Bang O.Y. 2010. A longterm follow-up study of intravenous autologous mesenchymal stem cell transplantation in patients with ischemic stroke. Stem Cells 28(6):10991106. <http://dx.doi.org/10.1002/stem.430><PMid:20506226>

Lee S.H., Kim Y., Rhew D., Kuk M., Kim M., Kim W.H. \& Kweon O.K. 2015. Effect of the combination of mesenchymal stromal cells and chondroitinase ABC on chronic spinal cord injury. Cytotherapy 17(10):1374-1383. <http:// dx.doi.org/10.1016/j.jcyt.2015.05.012> <PMid:26188966>

Lim J.H., Byeon Y.E., Ryu H.H., Jeong Y.H., Lee Y.M., Kim W.H., Kang K.S. \& Kweon O.K. 2007. Transplantation of canine umbilical cord blood-derived mesenchymal stem cells in experimentally induced spinal cord injured dogs. J. Vet. Sci. 8(3):275-282. <http://dx.doi.org/10.4142/jvs.2007.8.3.275> $<$ PMid:17679775>

Lorenz M.D. \& Kornegay J.N. 2011. Handbook of Veterinary Neurology. 14th ed. W.B. Saunders, Missouri, p.75-90. <http://dx.doi.org/10.1016/B9781-4377-0651-2.10004-9>

Lu P., Jones L.L. \& Tuszynski M.H. 2005. BDNF-expressing marrow stromal cells support extensive axonal growth at sites of spinal cord injury. Exp. Neurobiol. 191(2):344-360. <http://dx.doi.org/10.1016/j.expneurol.2004.09.018> $<$ PMid:15649491>

Maia J.M.A., Czeczko N.G., Ribas Filho J.M., Dietz U.A., Duck D., Ribas C.A.P.M., Santos E.A., Baptistella E., Wallbach T.Z., Vale J.R. \& Yagushita N. 2006. Estudo da cicatrização de suturas na bexiga urinária de ratos com e sem a utilização de extrato bruto de Jatropha gossypiifolia L. intraperitoneal. Acta Cir. Bras. 21(2 Supl.2):23-30. <http://dx.doi.org/10.1590/S010286502006000800005><PMid:17117274>

McKay R. 1997. Stem cells in the central nervous system. Science 276(5309):6671. <http://dx.doi.org/10.1126/science.276.5309.66><PMid:9082987>

McMahill B.G., Borjesson D.L., Sieber-Blum M., Nolta J.A. \& Sturges B.K. 2015. Stem cells in canine spinal cord injury: promise for regenerative therapy in a large animal model of human disease. Stem Cell Rev. Rep. 11(1):180-193. <http://dx.doi.org/10.1007/s12015-014-9553-9><PMid:25173879>

Mothe A.J. \& Tator C.H. 2012. Advances in stem cell therapy for spinal cord injury. J. Clin. Invest. 122(11):3824-3834. <http://dx.doi.org/10.1172/ JCI64124><PMid:23114605>

Neupane M., Chang C.C., Kiupel M. \& Yuzbasiyan-Gurkan V. 2008. Isolation and characterization of canine adiposederived mesenchymal stem cells. Tissue Eng. 14(6):1007-1015. <http://dx.doi.org/10.1089/ten.tea.2007.0207> $<$ PMid:19230125>

Nishida H., Nakayama M., Tanaka H., Kitamura M., Hatoya S., Sugiura K., Suzuki Y., Ide C. \& Inaba T. 2011. Evaluation of transplantation of autologous bone marrow stromal cells into the cerebrospinal fluid for treatment of chronic spinal cord injury in dogs. Am. J. Vet. Res. 72(8):1118-1123. <http://dx.doi. org/10.2460/ajvr.72.8.1118> <PMid:21801071>

Nishida H., Nakayama M., Tanaka H., Kitamura M., Hatoya S., Sugiura K., Harada Y., Suzuki Y., Ide C. \& Inaba T. 2012. Safety of autologous bone marrow stromal cell transplantation in dogs with acute spinal cord injury. Vet. Surg. 41(4):437-442. <http://dx.doi.org/10.1111/j.1532-950X.2011.00959.x> $<$ PMid:22548465>
Okada S., Nakamura M., Katoh H., Miyao T., Shimazaki T., Ishii K., Yamane J., Yoshimura A., Iwamoto Y., Toyama Y. \& Okano H. 2006. Conditional ablation of Stat3 or Socs 3 discloses a dual role for reactive astrocytes after spinal cord injury. Nat. Med.12(7):829-834.<http://dx.doi.org/10.1038/ nm1425><PMid:16783372>

Olson L. 2002. Medicine: clearing a path for nerve growth. Nature 416(6881):589590. <http://dx.doi.org/10.1038/416589a > <PMid:11948332>

Osako F.S.U., Akamine C., Santos M.M. \& Fragata F.S. 2008. Emergências neurológicas, p.317-329. In: Ibid. (Eds), Emergências e Terapia Intensiva Veterinária em Pequenos Animais. 23aㅡ ed. Roca, São Paulo.

Pal R., Gopinath C., Rao N., Banerjee P., Krishnamoorthy V., Venkataramana N.K. \& Totey S. 2010. Functional recovery after transplantation of bone marrow-derived human mesenchymal stromal cells in a rat model of spinal cord injury. Cytotherapy 12(6):792-806. <http://dx.doi.org/10.3109/14 653249.2010.487899><PMid:20524772>

Park E.H., White G.A. \& Tieber L.M. 2012. Mechanisms of injury and emergency care of acute spinal cord injury in dogs and cats. J. Vet. Emerg. Crit. Care 22(2):160-178. <http://dx.doi.org/10.1111/j.1476-4431.2012.00723. $\mathrm{x}><$ PMid:23016808>

Penha E.M., Meira C.S., Guimarães E.T., Mendonça M.V., Gravely F.A., Pinheiro C.M., Pinheiro T.M., Barrouin-Melo S.M., Ribeiro-dos-Santos R. \& Soares M.B. 2014. Use of autologous mesenchymal stem cells derived from bone marrow for the treatment of naturally injured spinal cord in dogs. Stem Cells 2014:437521. <http://dx.doi.org/10.1155/2014/437521> <PMid:24723956>

Penning V., Platt S.R., Dennis R., Cappello R. \& Adams V. 2006. Association of spinal cord compression seen on magnetic resonance imaging with clinical outcome in 67 dogs with thoracolumbar intervertebral disc extrusion. J. Small Anim. Pract. 47(11):644-650. <http://dx.doi. org/10.1111/j.1748-5827.2006.00252.x ><PMid:17076787>

Pluchino S., Zanotti L., Deleidi M. \& Martino G. 2005. Neural stem cells and their use as therapeutic tool in neurological disorders. Brain Res. Rev. 48(2):211-219. <http://dx.doi.org/10.1016/j.brainresrev.2004.12.011> $<$ PMid:15850660>

Prado C.V.G.B. 2016. Combination of stem cells from deciduous teeth and electroacupuncture in dogs whith chronic spinal cord injury. Tese de Doutorado. Disponível em <http://www.teses.usp.br/teses/disponiveis/10/10132/ tde-21032017-162328/pt-br.php> Acesso em 18 out. 2017.

Quertainmont R., Cantinieaux D., Botman O., Sid S., Schoenen J. \& Franzen R. 2012. Mesenchymal stem cell graft improves recovery after spinal cord injury in adult rats through neurotrophic and pro-angiogenic actions. J. PlosOne. 7(6):e39500. <PMid:22745769>

Rasouli A., Bhatia N., Dinh P., Cahill K., Suryadevara S. \& Gupta R. 2009. Resection of glial scar following spinal cord injury. J. Orthop. Res. 27(7):931-936. <http://dx.doi.org/10.1002/jor.20793> <PMid:19062171>

Rolls A., Shechter R., London A., Segev Y., Jacob-Hirsch J., Amariglio N., Rechavi G. \& Schwartz M. 2008. Two faces of chondroitin sulfate proteoglycan in spinal cord repair: a role in microglia/macrophage activation. J. Plos Med. 5(8):1262-1277. <PMid:18715114>

Romanov Y.A., Darevskaya A.N., Merzlikina N.V. \& Buravkova L.B. 2005. Mesenchymal stem cells from human bone marrow and adipose tissue: isolation, characterization, and differentiation potentialities. Bull. Exp. Biol. Med. 140(1):138-143. <http://dx.doi.org/10.1007/s10517-0050430-z><PMid:16254640>

Sarmento C.A., Rodrigues M.N., Bocabello R.Z., Mess A.M. \& Miglino M.A. 2014. Pilot study: Bone marrow stem cells as a treatment for dogs with chronic spinal cord injury. Regen. Med. Res. 2(1):9. <http://dx.doi. org/10.1186/2050-490X-2-9><PMid:25984337>

Screven R., Kenyon E., Myers M.J., Yancy H.F., Skasko M., Boxer L., Bigley 3rd E.C., Borjesson D.L. \& Zhu M. 2014. Immunophenotype and gene expression profile of mesenchymal stem cells derived from canine adipose tissue and 
bone marrow. Vet. Immunol. Immunopathol. 161(1/2):21-31. <http:// dx.doi.org/10.1016/j.vetimm.2014.06.002><PMid:25026887>

Sharma K., Selzer M.E. \& Li S. 2012. Scar-mediated inhibition and CSPG receptors in the CNS. Exp. Neurol. 237(2):370-378. <http://dx.doi.org/10.1016/j. expneurol.2012.07.009><PMid:22836147>

Sharp N.J.H. \& Wheeler S.J. 2005. Small Animal Spinal Disorders: Diagnosis and Surgery. 2nd ed. Elsevier Mosby, Philadelphia, p.81-91 <http://dx.doi. org/10.1016/B978-0-7234-3209-8.50010-8>.

Shields L.B.E., Zhang Y.P., Burke D.A., Gray R. \& Shields C.B. 2008. Benefit of chondroitinase $\mathrm{ABC}$ on sensory axon regeneration in a laceration model of spinal cord injury in the rat. Surg. Neurol. 69(6):568-577. <http://dx.doi. org/10.1016/j.surneu.2008.02.009 ><PMid:18486695>

Spaeth E., Klopp A., Dembinski J., Andreeff M. \& Marini F. 2008. Inflammation and tumour microenvironments: Defining the migratory itinerary of mesenchymal stem cells. Gene Ther. 15(10):730-738. <http://dx.doi. org/10.1038/gt.2008.39> <PMid:18401438>

Takemitsu H., Zhao D., Yamamoto I., Harada Y., Michishita M. \& Arai T. 2012. Comparison of bone marrow and adipose tissue-derived canine mesenchymal stem cells. BMC Vet. Res. 8(1):150. <http://dx.doi.org/10.1186/17466148-8-150><PMid:22937862>

Tamura K., Harada Y., Nagashima N., Itoi T., Ishino H., Yogo T., Nezu Y., Hara Y., Suzuki Y., Ide C. \& Tagawa M. 2012. Autotransplanting of bone marrowderived mononuclear cells for complete cases of canine paraplegia and loss of pain perception, secondary to intervertebral disc herniation. Exp. Clin. Transplant. 10(3):263-272. <http://dx.doi.org/10.6002/ect.2011.0151> <PMid:22631064>

Thrall M.A. 2015. Hematologia e Bioquímica Clínica Veterinária. Vol.1. 2ª ed. Roca, Rio de Janeiro, p.80.
Tom V.J., Sandrow-Feinberg H.R., Miller K., Santi L., Connors T., Lemay M.A. \& Houlé J.D. 2009. Combining peripheral nerve grafts and chondroitinase promotes functional axonal regeneration in the chronically injured spinal cord. J. Neurosci. 29(47):14881-14890. <http://dx.doi.org/10.1523/ JNEUROSCI.3641-09.2009><PMid:19940184>

Vieira N.M., Brandalise V., Zucconi E., Secco M., Strauss B.E. \& Zatz M. 2010. Isolation, characterization, and differentiation potential of canine adipose-derived stem cells. Cell Transplant. 19(3):279-289. <http://dx.doi org/10.3727/096368909X481764><PMid:19995482>

Villanova Junior J.A. 2013. Transplante de células tronco derivadas do tecido adiposo em ratos submetidos à lesão medular compressiva, com e sem tratamento com corticoide. Tese de Doutorado. Disponível em <http:// hdl.handle.net/1884/33779> Acesso em 15 mar. 2015.

Webb A.A., Ngan S. \& Fowler J.D. 2010. Spinal cord injury I: a synopsis of the basic science. Can. Vet. J. 51(5):485-492. <PMid:20676289>

Willerth S.M. \& Sakiyama-Elbert S.E. 2008. Cell therapy for spinal cord regeneration. Adv. Drug Deliv. Rev. 60(2):263-276. <http://dx.doi org/10.1016/j.addr.2007.08.028> <PMid:18029050>

Wright K.T., Masri W.E., Osman A., Chowdhury J. \& Johnson W.E.B. 2011. Bone marrow for the treatment of spinal cord injury: mechanisms and clinical applications. Stem Cells 29(2):169-178. <http://dx.doi.org/10.1002/ stem.570><PMid:21732476>

Yu P., Huang L., Zou J., Zhu H., Wang X., Yu Z., Xu X.M. \& Lu P.H. 2007. DNA vaccine against $\mathrm{NgR}$ promotes functional recovery after spinal cord injury in adult rats. Brain Res. 1147:66-76. <http://dx.doi.org/10.1016/j. brainres.2007.02.013><PMid:17362886>

Zuk P.A., Zhu M., Ashjian P., De Ugarte D.A., Huang H.I., Mizuno H., Alfonso Z.C., Fraser J.K., Benhaim P. \& Hedrick M.H. 2002. Human adipose tissue is a source of multipotent stem cells. Mol. Biol. Cell 13(12):4279-4295. <http://dx.doi.org/10.1091/mbc.e02-02-0105> <PMid:12475952> 